\section{Civilizar}

ISSN 1657-8953 e-ISSN: 2619-189X

\title{
Responsabilidad de los Administradores en las Entidades Sin Ánimo de Lucro*
}

\author{
Responsibility of the Administrators in Non-Profit Organizations
}

Mariela González Robles

Artículo de reflexión desarrollado como trabajo de grado para optar por el título de Magíster en Derecho con énfasis en Derecho Privado de la Universidad del Rosario, dirigida por el profesor Dr. Edgar Iván León Robayo. Se ubica dentro del proyecto de investigación Problemas Contemporáneos del Derecho Comercial, en la línea de investigación en Derecho Comercial del Grupo de Investigación en Derecho Privado de la Facultad de Jurisprudencia de la Universidad del Rosario. $\S$ Abogada egresada de la Universidad Incca de Colombia. Especialista en Derecho Administrativo y Constitucional de la Universidad Católica de Colombia. Candidata a magíster en Derecho con énfasis en Derecho Privado en la Universidad del Rosario.

Correo electrónico:

mariela.gonzalez@urosario.edu.co

(iD) 0000-0002-5651-0291

Cómo citar:

González-Robles, M. (2019). Responsabilidad de los administradores en las Entidades Sin Ánimo de Lucro (ESAL). Civilizar: Ciencias Sociales y Humanas, 19(37), 11-20. https://doi.org/10.22518/ usergioa/jour/ccsh/2019.2/a05

Recibido: 17/10/2018 Revisado: 05/11/2019 Aceptado: 12/11/2019

\section{Resumen}

Las Entidades Sin Ánimo de Lucro (ESAL) son organizaciones creadas para el beneficio de comunidades vulnerables y su buen funcionamiento es responsabilidad de su administrador. Pero ¿hasta dónde llega la responsabilidad de un administrador de este tipo de entidades? Este artículo analizará las normas que rigen a las sociedades comerciales y las ESAL, así como los alcances, particularidades e interpretaciones que enmarcan la responsabilidad de los administradores de este tipo de entidades. La regulación a las ESAL y a sus representantes es un ejemplo de caso en que la analogía ofrece soluciones a vacíos normativos y ayuda a armonizar las ramas del derecho en beneficio de la organización y su fin.

\section{Palabras Clave}

Entidades Sin Ánimo de Lucro, ESAL, estatutos, Régimen de responsabilidad, administrador, culpabilidad, regulación interna, sociedades comerciales.

\section{Abstract}

Non-Profit Organizations (NOPs) were created to benefit vulnerable communities; their proper functioning is their administrators' responsibilities. Nevertheless, how far does the responsibility of an administrator of this type of entity go? This article analyzes the regulations that govern commercial firms and NPOs, as well as the scope, particularities and interpretations that frame the responsibility of the administrators of Non-Profit Organizations. Regulating NPOs and their representatives is an example case in which analogy offers solutions to regulatory gaps and helps to harmonize the branches of law for the organizations' benefit and their purpose.

\section{Keywords}

Non-Profit Organizations, NPO, statutes, responsibility, liability regime, administrator, culpability. 


\section{Introducción}

Las Entidades sin Ánimo de Lucro (ESAL) se originaron durante la Colonia, cuando las instituciones de caridad surgieron en beneficio de los menos favorecidos. Hoy, organizaciones con fines similares funcionan bajo el amparo normativo establecido en la Constitución Política'; el Código Civil (art. 633) donde se les clasifica en corporaciones ${ }^{2} y$ fundaciones de beneficencia pública ${ }^{3}$ y en leyes y decretos que señalan los requisitos de creación, funcionamiento, relación entre miembros y órganos de dirección, control y administración: Ley 22 de 1987, los Decretos o54 de 1974; 301 de 1978; 361 de 1987; 1318 de 1988; 2344 de 1988; 1529 de 1990 y 0427 de 1996; los Decretos Distritales o59 de 199 y 1663 de 1995; los artículos 40 a 45 del Decreto 2150 de 1995, el artículo 166 del Decreto o19 de 2012 y la Circular Externa de la Superintendencia de Industria y Comercio No. 4 de 2007, entre otras normas especiales.

La inspección ${ }^{4}$, control $^{5}$ y vigilancia ${ }^{6}$ de las ESAL, se encuentran estipuladas en la Constitución Política (num. 26, art. 189), en cabeza del Presidente de la República7. Sin embargo, no es el único medio de control, porque se regulan también por estatutos y acuerdos de voluntad que deben estar constituidos en escritura pública, debidamente registrados ante la Cámara de Comercio de la ciudad donde se crean o en las gobernaciones de los Departamentos donde tengan su domicilio principal (la Alcaldía Mayor en el caso de Bogotá) ${ }^{8}$.

De cara a la actividad u objeto que pretenden desarrollar las ESAL, se clasifican en gremiales ${ }^{9}$, agropecuarias y de campesinos ${ }^{10}$, de beneficencia ${ }^{11}$, tecnológicas, juveniles ${ }^{12}$, de bienestar social ${ }^{13}$, democráticas y participativas ${ }^{14}$, cívicas y comunitarias ${ }^{15}$, sociales $^{16}$, entre otras (Decreto 427 de 1996, art. 2). Independientemente de su clasificación, son personas jurídicas con "capacidad de ejercer derechos y contraer obligaciones, que pueden ser representadas judicial y extrajudicialmente, con sujeción a las disposiciones legales y a sus propios estatutos" (Alcaldía Mayor de Bogotá, 2013. p. 21). Por tanto, en las ESAL hay un administrador que funge como representante legal ${ }^{17}$.

Ahora bien, estas entidades cuentan con el componente normativo arriba señalado, pero hay ausencia general de regulación y desarrollo en torno a la responsabilidad y las sanciones derivadas de las conductas contrarias a la ley, los estatutos y el objeto de las ESAL por parte de sus administradores. Esto no ocurre con las ESAL que tienen regulación especial, ni con las sociedades civiles (Ley 222 de 1995, art. 1) y comerciales de Colombia, ubicadas dentro del régimen de responsabilidad de los administradores que determina la Ley 222 de 1995 y el establecimiento de sanciones dispuestas en el Código de Comercio (Código de Comercio, arts. 308, 404 y 447).

Los administradores de las ESAL, así como los de las sociedades civiles y comerciales, trabajan para generar desarrollo, auge y buen funcionamiento de la entidad que administran, tanto como el "buen hombre de negocios". A la luz de esta afirmación, surgen los siguientes interrogantes: ¿Los entes que vigilan y controlan las ESAL son eficientes? ¿Cuál es el tope o límite que tienen los administradores de las ESAL frente a sus facultades y responsabilidad? ¿Cuál es el ámbito sancionatorio aplicable a los administradores de las ESAL? ¿Tienen los administradores de las ESAL beneficios especiales en la ley colombiana o hay un trato diferencial con relación a los administradores de las sociedades comerciales y civiles? Inquietudes que se resolverán partiendo de las generalidades de la ESAL, del administrador, sus funciones y las responsabilidades en que puede incurrir. Se abordará desde el régimen aplicable a los administradores y la legitimidad del administrador, para culminar con la conveniencia de regulaciones internas; tópicos que se desarrollaran a partir de un análisis comparativo entre los códigos, las leyes y normas existentes tanto para las ESAL como para las sociedades civiles, regidas por normatividad contenida en el Código Civil, y las comerciales, que se rigen por las normas contenidas en el Código de Comercio.

\section{Generalidades de las ESAL}

Las ESAL son solo una de las múltiples formas de asociación existentes en Colombia. Se trata de entidades en las que algunos asociados suman sus voluntades con un objeto específico en beneficio de la sociedad. Su clasificación obedece a la actividad que realizan y se definen en cuatro categorías: fundaciones, asociaciones y corporaciones, veedurías ciudadanas $^{18}$, entidades de economía solidaria y las entidades extranjeras de derecho privado sin ánimo de lucro con domicilio en el exterior. En cualquier caso deben dejar manifiesta la estructuración de su 
patrimonio, conformación de mayorías para votación, representación legal, actos de representación legal, obligatoriedad de lo estatutos, la disminución de sus miembros y la disolución y liquidación (Código Civil, arts. 637-641, 648 y 649) que disponen sus miembros en los estatutos por acuerdo de voluntades y con base en lo señalado en la ley (Decreto 530 de 2015, art. 11) ${ }^{19}$. Estos factores deben ser consignados en los estatutos de constitución y funcionamiento de la entidad, pues ayudarán a definir las facultades, controlar las acciones de cada miembro y colaborador y asegurará transparencia en los procesos que adelanta.

Como ya lo anunciamos, las ESAL cuentan con órganos de dirección, administración y control conformados por un grupo de individuos con derechos y responsabilidades estatutarias, con la posibilidad de tomar decisiones por votación. Por ejemplo, el consejo de fundadores, que representa a todos los fundadores y asociados de la entidad y entre sus funciones está presentar los estados financieros y el presupuesto a la Asamblea General, por ser el órgano supremo de la entidad y quien toma la decisión de aprobar, en cuyo caso serán ejecutados por el administrador, o improbar los documentos e informes que se le presentan.

Los diferentes órganos de la entidad comparten responsabilidades de la gestión, incluido el administrador de la ESAL; tienen el deber y la obligación de hacer cumplir los estatutos, controlar los recursos y gestionar en beneficio del objeto de la ESAL; entre sus funciones está "hacer cumplir las disposiciones adoptadas por la asamblea general, acompañar en el manejo de la entidad al representante legal además de velar porque éste cumpla cabalmente sus funciones" (Alcaldía Mayor de Bogotá, 2013, p. 31).

No obstante, es importante precisar en debida forma las obligaciones, deberes, responsabilidades $\mathrm{y}$ sanciones que puede tener el administrador de la ESAL, porque en algunos casos el representante legal asume como administrador, lo que se presta para confusiones entre sus funciones, atribuciones y responsabilidad.

Las funciones de gestión que ejerce la Junta, son como cuerpo colegiado, y no las personas que la componen. El verdadero administrador a quien el estatuto le asigna las funciones de gestión es la junta directiva y así sus miembros no tienen ni cumplen funciones de administración individualmente consideradas. (Neira, 1988, p. 156).
Se advierte al lector que hay una excepción para las ESAL que se rigen por normas especiales, con relación al reconocimiento de la personería jurídica (Decreto 2150 de 1995, art. 45). Por ejemplo, las que giran alrededor de la seguridad social están reguladas por la Ley 100 de 1993; lo que tiene que ver con asuntos de educación formal y no formal se rigen por la Ley 115 de 1994; las que tienen que ver con la libertad religiosa y cultos, se rigen por la Ley 133 de 1995, entre otras; las demás personas jurídicas son reguladas por la ley expresamente y en forma específica, por lo tanto, no son objeto de estudio para este artículo.

\section{El administrador de las ESAL y sus funciones}

El administrador y/o representante legal es la persona que tiene a su cargo la responsabilidad de gestionar, actuar y trabajar con bienes ajenos, amparado en sus funciones administrativas y en cumplimiento del objeto y fin altruista impuesto por la ESAL (Código Civil, art. 640; Decreto 2150 de 1995, art. 43). Al respecto, Reyes (1996) comenta que el administrador es la persona que administra bienes ajenos. A manera de ejemplo, en un concepto sobre la figura de administración, la Superintendencia de Sociedades (1997) expresó: "serán administradores si ejercen funciones administrativas o si las detentan, de donde resulta que es administrador quien obra como tal y también lo es quien está investido de facultades administrativas" (p. 20).

En tal sentido, la administración puede darse de forma individual o colegiada y en las ESAL son válidas ambas opciones en términos de actuaciones internas (actos de gestión) y externas (actos de representación). De hecho, hay autores que lo señalan:

La gestión y la representación se diferencian: por su ámbito, ya que la primera mira al interior de la sociedad, aspecto interno, mientras la segunda mira hacia el exterior, aspecto externo; por su contenido porque mientras la gestión es una facultad elástica, capaz de limitaciones, la representación es una facultad rígida, de contenido típico, ilimitable; y por su nota peculiar, porque la gestión es una cuestión de deber mientras la representación es una cuestión de poder. (Garrigues, 1947, p. 547).

En otras palabras, la representación puede recaer en el presidente, director, gerente y en un grupo de potenciales suplentes de ellos (Gaitán Sánchez, 2014), mientras que, frente a la ciudadanía, 
donadores, o incluso el mismo Estado, es el administrador quien dirige, gestiona, administra y vela por el cumplimiento y función de los bienes y del beneficio social que persigue la entidad.

Una de las funciones generales de un administrador es desarrollar su trabajo como un buen hombre de negocios, capaz de impulsar, desarrollar y hacer crecer la entidad que administra con responsabilidad. Su actuar debe estar cobijado por la confidencialidad, reserva de la información; actividades, habilidades y técnicas para desarrollar su objeto, y proteger los intereses de la entidad. Debe actuar con profesionalismo, ética, disposición, entrega de sus conocimientos, capital y capacidad humanos, que le permitan evaluar situaciones para tomar decisiones favorables para la ESAL.

Los derechos y/o principios fundamentales, el orden jurídico en prevalencia del interés público, al amparo de buenas prácticas profesionales, éticas y de buena fe dirigidas a la protección de derechos de terceros se deben hacer valer, respetar y salvaguardar en desarrollo de la gestión y función de la administración; sumado a la prohibición de no abusar de los derechos propios (Sentencia T-468 de 2003). La administración debe ejercer sus actuaciones de forma diligente, en beneficio e interés de la entidad, al tiempo que propende por el cabal desarrollo y cumplimiento del objeto altruista, gremial o de beneficio a un grupo social determinado. Esto es reafirmado por autores como Llebot (2008), quien dice que el comportamiento leal, honesto y comprometido del administrador garantiza que este evite caer en un conflicto de intereses; lo que implica que el ejercicio pleno de la entidad frente al conglomerado social, con sus responsabilidades y limitaciones, recae sobre el administrador.

Otra de las funciones que le asiste a los administradores de las ESAL es la obligatoriedad de llevar una documentación, presentar estados financieros, balance general, informes de gestión, estado de resultados, informe de ejecución del año anterior, estados de cambio en la situación patrimonial, estado de cambios en el capital de trabajo, estado de flujo de efectivo, ejecución presupuestal para el año que se inicia. Así mismo, debe presentar informes ante la junta directiva o asamblea de socios y ante las entidades de vigilancia y control, cuando estos lo requieran (Decreto 2649 de 1993, arts. 22 y 32; Ley 222 de 1995, art. 47).
Es claro que el administrador de las ESAL se debe regir por el objeto de la ESAL, por sus funciones y facultades designadas de tres formas. La primera señala los actos de representación (Decreto 2150 de 1995, arts 42 y 43; Código Civil, art. 638) y representación legal de las corporaciones (Código Civil, art. 639). La segunda es la contenida en los estatutos (Código Civil, art. 636). La tercera forma corresponde al contrato que suscribió con la entidad que determina las cláusulas, condiciones y características especiales para la Administración de la ESAL, en atención a las necesidades y requerimientos de las partes contratantes y con fundamento en la expresión de la autonomía de la voluntad de los otorgantes. Al respecto la Corte Constitucional expresó que:

Los particulares, libremente y según su mejor conveniencia, son los llamados a determinar el contenido, el alcance, las condiciones y modalidades de sus actos jurídicos. Al proceder a hacerlo deben observar los requisitos exigidos, que obedecen a razones tocantes con la protección de los propios agentes, de los terceros y del interés general de la sociedad. (Sentencia T-338 de 1993).

Según Hinestrosa (2013), un adecuado uso de la autonomía de la voluntad privada contribuiría en la regulación de aspectos internos que no están contenidos en las normas y que pueden estructurar el régimen general de responsabilidad de las ESAL. Por ejemplo, con relación a los deberes y obligaciones de sus miembros; reuniones, actas e impugnación de decisiones, temas de control interno así como la inspección y vigilancia sobre los actos, deberes y obligaciones del administrador. Por otro lado, el uso y aplicación del principio de analogía, a partir de las normas existentes para las sociedades civiles y mercantiles, podría robustecer las herramientas jurídicas de la responsabilidad de los administradores de la ESAL. Es por ello que se puede observar la analogía iuris que "se encuentra referida a la aplicación de una regla general que se utilizó en determinados casos, y que por tal motivo se considera que debe aplicarse en otros semejantes" (León, 2015, p. 125). Por lo tanto, el régimen general de responsabilidades de los administradores de las ESAL puede nacer a partir de la autonomía privada de la voluntad, el uso de la analogía y hasta la costumbre, donde cada una aporta para identificar los escenarios descubiertos por la norma y cubiertos por estas, encontrando la solución a los vacíos normativos. 


\section{Clases de responsabilidad en las que puede} incurrir el administrador

El administrador de la ESAL enfrenta varias responsabilidades con relación a la ejecución de su administración frente a los asociados, empleados y terceros. Con los tres tiene derechos y obligaciones en el marco del objeto de la ESAL y se advierte de sus actuaciones la capacidad de análisis, conceptualización, liderazgo, lealtad, honestidad, trabajo en equipo, logro de metas y objetivos estratégicos para robustecer la organización. De ahí que su responsabilidad no se limite al plano personal, sino que es ilimitada, solidaria, patrimonial y puede extenderse al ámbito civil (Código Civil Títulos XXXVI y XXXIV), penal (Código Penal, arts 21-24, 314-317; Ley 599 de 2000) ${ }^{20}$ y tributario (Estatuto Tributario, arts 19 y 794; Ley 1819 de 2016). Además, de tener inversión, donaciones o relación con dineros estatales, su responsabilidad también puede ser administrativa (Ley 1437 de 2011; Decreto 059 de 1991, arts 25, 39 y 40), fiscal y disciplinaria.

Frente a estas responsabilidades, la ley (Código Civil, art. 2341; Ley 222 de 1995, art. 24) señala las diferentes acciones judiciales que los afectados pueden iniciar contra una sociedad o entidad para obtener, por ejemplo, una indemnización por perjuicios. Así, la responsabilidad civil se divide en dos: una contractual y otra extracontractual. La primera proviene del incumplimiento de las cláusulas de un contrato y genera un daño. Para la segunda, según Pérez (1996) son tres "las condiciones tradicionalmente exigidas para que se comprometa la responsabilidad civil de una persona: daño, culpa y relación de causalidad entre ésta y aquel" (p. 57). Esto va en concordancia con lo que la ley señala: "el que ha cometido un delito o culpa, que ha inferido daño a otro, es obligado a la indemnización, sin perjuicio de la pena principal que la ley imponga por la culpa o el delito cometido" (Código Civil, art. 2341).

De acuerdo con las normas comerciales, una responsabilidad de los administradores es responder solidaria e ilimitadamente a la sociedad, a los socios y/o terceros cuando se les ocasionen perjuicios por dolo o culpa. No obstante, para quienes no hayan tenido conocimiento de la acción u omisión no se les aplicarán estas normas (Código de Comercio, art. 200; Ley 222 de 1995, art. 24). Es decir, cuando el administrador por y bajo sus propios intereses haya actuado por fuera de sus funciones, obligaciones, y contra la ley y/o los estatutos, deberá responder por su conducta culposa o dolosa (Neira, 1988). La excepción a este caso sería que el administrador no hubiera participado en el daño culposo o doloso, pero incluso entonces enfrentaría la responsabilidad civil ante la entidad que administra. Esto aplica si la actuación no resultó en daños a terceros, si los hubiera, tendrá que analizarse su responsabilidad penal, fiscal, administrativa o civil según corresponda al caso.

\section{Régimen aplicable a los administradores de las ESAL a partir de sus responsabilidades}

Por sus características especiales, las ESAL fueron eximidas de aplicárseles el capítulo II del artículo 45 del Decreto 2150. Ante este vacío normativo, se ha sugerido el uso y aplicación del principio de analogía que está tipificado en el artículo de la Ley 153 de 1887, el cual dispone que, ante una carencia de normas que regulen un asunto particular, se pueda aplicar las leyes que regulen casos semejantes, en armonía con el artículo 48 de la misma norma. Al respecto, la Corte Constitucional expresó:

La analogía es la aplicación de la ley a situaciones no contempladas expresamente en ella, pero que sólo difieren de las que sí lo están en aspectos jurídicamente irrelevantes, es decir, ajenos a aquéllos que explican y fundamentan la ratio juris o razón de ser de la norma. (Sentencia C-083 de 1995).

No obstante lo anterior, la Superintendencia de Sociedades (2016), manifestó su negativa para la aplicación al principio de analogía con relación a la Responsabilidad de los Administradores de las ESAL por considerar que estas cuentan con su propia normatividad, además de regirse por sus estatutos y fundamentalmente porque no persiguen una obtención de lucro, como sí sucede con las sociedades mercantiles. Es justamente por esta marcada diferencia y porque son normas de uso e interpretación restrictiva que no admiten el uso de la analogía. No obstante, al ser un concepto que no tiene fuerza vinculante se considera relevante retomar la sugerencia del uso de la analogía para dirimir los conflictos que se susciten en las ESAL por y a causa de la responsabilidad de los administradores ya que "el Código no contiene ninguna clase de restricción respecto de la utilización de normas imperativas al hacer uso de la analogía, lo cual da libertad al operador jurídico para su aplicación ante las lagunas de la ley” (León, 2015, p. 124). 
Para regular la responsabilidad de los administradores de las ESAL, en uso del principio de analogía, es menester tomar en conjunto el artículo 200 del Código Comercio Colombiano, el 24 y el 73 de la Ley 222 de 1995 y el 2341 del Código Civil, sumado a los estatutos de las ESAL y a la autonomía de la voluntad, por dar algunos ejemplos. Esto permitirá hallar la respuesta jurídica efectiva ante un hecho que conlleve responder a terceros por el actuar de sus administradores. Por el contrario, si los hechos dañosos cometidos por los administradores han sido ocasionados por su negligencia, imprudencia, falta de cuidado o conocimiento, por conflicto de interés y por fuera de los parámetros legales y estatutarios, el administrador deberá responder por el hecho propio generador del daño (Santos, 1988). Ahora bien, si las conductas reprochables del administrador ocasionan un detrimento a terceros y a la ESAL de tal forma que se viole el interés general y trascienda en violación de los derechos Constitucionales, resulta necesario crear mecanismos de vigilancia y supervisión constantes a las actividades y conductas de los administradores con la única finalidad de contar con su debida y calificada diligencia.

Si bien no hay normatividad expresa general para la responsabilidad de los administradores de las ESAL, no implica que no haya forma de hacerlos responsables de sus actos. Es cuestión de ampliar el rango de interpretación y valoración normativo por parte del operador judicial, potencializando el ejercicio de inspección, control y vigilancia respecto de las actividades que desarrolla el administrador, además de fijar un marco normativo sancionatorio de cara a los actos de administración y/o representación legal.

Así por ejemplo, la Corte Suprema de Justicia (Sentencia 05001-3103-005-2000-00177-01, 2011) se pronunció frente a la responsabilidad de los administradores por la evasión del pago de salario y prestaciones a trabajadores en caso de disolución. Quienes figuraban como representantes de la empresa que se liquidaba tuvieron que responder por el mal manejo que se les dio a los recursos provenientes de dicha liquidación, puesto que recibieron dinero por concepto de la venta de activos y no los utilizaron para amortizar el pago de los salarios adeudados a los trabajadores.

\section{La legitimidad del administrador de la ESAL.}

Aquella está sujeta a la Constitución, la ley, los estatutos y su forma de vinculación, ya por contrato laboral, de prestación de servicios o por mandato. Cada una de estas formas de vinculación per se contiene un conjunto de derechos, deberes y obligaciones sumado a las funciones que legalizan su posición de administrador en razón a que debe quedar registrado ante la Cámara de Comercio en esa calidad. Al respecto, Díaz (1958) expresa que los administradores son, ante todo, "mandatarios comerciales que mantienen un doble orden de relaciones: de representación necesaria, fundadas respectivamente en el mandato, en la ley, ya que las entidades en su condición de personas jurídicas se consideran representadas por ellos" (p. 49).

Como se anotaba, el mandato es una forma de estar legitimado para actuar como administrador de la ESAL. Es evidente que este vínculo constituye el fundamento de la responsabilidad contractual según la ley:

Los miembros de la administración y los fiscales revisores son solidariamente responsables para con cada uno de los accionistas y acreedores de la sociedad, de todos los daños que les hubieren causado por faltar voluntariamente a los deberes que les impone sus funciones respectivas. (Ley 58 de 1931, art. 41).

Como consecuencia, la legitimidad no solo está concebida en términos legales, sino también con relación a la jerarquía en los niveles superiores (Junta Directiva y Asamblea General) e inferiores (subalternos); para ello se implementan prácticas justas al interior de la entidad, que permitan a todos los integrantes sentirse identificados y comprometidos con el cumplimiento de roles, metas y objeto altruista que persigue la ESAL.

\section{Conveniencia de regulaciones internas}

Es importante instar a las ESAL constituidas y a quienes intentan iniciar una a que innoven y creen regulaciones internas que contemplen un acápite especial sobre la responsabilidad de los administradores; donde expongan obligaciones, deberes, derechos, así como sanciones. Así mismo, se precisa de una regulación sobre la protección de información privilegiada, acuerdos de confidencialidad, conflictos de intereses, participación en competencias, actos de corrupción y la constitución de seguros 
patrimoniales que blinden a la entidad de daños a terceros; todo en aras de proteger a la ESAL de prácticas administrativas irregulares, deficientes y/o ilegales por las que deba responder de forma solidaria.

Dentro de los reglamentos internos de las ESAL es factible generar códigos de ética y buen gobierno que regulen la transparencia, solución de conflictos internos y externos; que integren planes de control de la gestión, pautas de comportamiento y respeto parar facilitar la ejecución de las funciones y el cumplimiento del objeto de la entidad, dentro de un buen clima laboral. Esto contribuirá al cumplimiento de metas, focalización del objeto, mejoramiento interno y externo, y crecimiento de la entidad. Estas estrategias constituyen una excelente forma de proyección para la obtención de la calificación meritoria de acuerdo con lo contemplado en la Ley 1819 de 2016, en concordancia con Bermúdez (2003):

La gestión de los administradores de las ESAL será evaluada, en sus actos de gestión, rendición de cuentas a todos los niveles, así como la vigilancia de los funcionarios subordinados, todo con miras a entregar un óptimo resultado en la proyección y cumplimiento del objeto altruista de la entidad que se administra. (p. 17).

\section{Conclusiones}

Es evidente la falta de un régimen jurídico general e integral de responsabilidad de los administradores de las ESAL. Por lo tanto, una sugerencia factible es aplicar el principio de analogía frente a los vacíos normativos, además de implementar medidas regulatorias internas, junto con la adopción de un código de ética y buen gobierno. Esto incluye la activación de pólizas de responsabilidad y de cláusulas contractuales anticorrupción que contribuyen a la protección de las ESAL, de cara a la gestión del administrador, y mitiguen el deterioro administrativo de estas entidades.

Por otra parte, es indispensable contar con un régimen sancionatorio general que abarque la responsabilidad de los administradores de las ESAL, para darles un trato igualitario frente a los pares de normatividad especial y a los que pertenecen a sociedades civiles y comerciales. No basta con la mera inspección, control y vigilancia que el gobierno tiene a cargo, puesto que ella se dirige a la entidad, como persona jurídica, y no a la actividad y gestión que desempeña y ejerce el administrador, como persona natural.

\section{Referencias}

Alcaldía Mayor de Bogotá. (s.f.). Definiciones del sistema de información de personas jurídicas. Recuperado de http://www.alcaldiabogota.gov.co/SPJ/home/ servicios.htm

Alcaldía Mayor de Bogotá. (2013). Manual de entidades sin ánimo de lucro. Recuperado de http://www. alcaldiabogota.gov.co/SPJ/manual/ManualESAL2013.pdf

Alessandri, A. (2010). De la responsabilidad extracontractual en el derecho civil. Santiago de Chile, Chile: Editorial Libromar.

Bermúdez Gómez, H. (2003). Responsabilidad de los administradores de las sociedades [Working paper]. Bogotá, Colombia: Universidad Javeriana. Recuperado de http://www.javeriana.edu.co/personales/ hbermude/ensayos/RESADD.doc

Belalcázar, E., y Riascos, L. (2011). Derecho de las Personas Jurídicas Sin Ánimo de Lucro ONG Asociaciones, Corporaciones, Fundaciones Clubes Sociales. Bogotá, Colombia: Librería Ediciones del Profesional Ltda.

Decreto 410 (1971, marzo 27). Por el cual se expide el Código de Comercio. Presidencia de la República [Colombia]. Diario Oficial No. 33.339 del 16 de junio de 1971. Bogotá, Colombia. Recuperado de http:// www.secretariasenado.gov.co/senado/basedoc/ codigo_comercio.html

Decreto 624 (1989, marzo 30). Por el cual se expide el Estatuto Tributario de los Impuestos Administrados por la Dirección General de Impuestos Nacionales. Presidencia de la República [Colombia]. Diario Oficial No. 38.756 de 30 de marzo de 1989. Recuperado de http://www.secretariasenado.gov.co/ senado/basedoc/estatuto_tributario.html

Decreto 2649 (1993, diciembre 29). Por el cual se reglamenta la Contabilidad en general y se expiden los principios o normas de contabilidad generalmente aceptados en Colombia. Presidencia de la República [Colombia]. Diario Oficial 41156 de diciembre 29 de 1993. Recuperado de https://bibliotecadigital. ccb.org.co/bitstream/handle/11520/13812/Decreto $\% 202649 \%$ 2ode $\% 201993$.pdf?sequence $=1 \&$ isAllowed=y

Decreto 2150 (1995, diciembre 05]. Por el cual se suprimen y reforman regulaciones, procedimientos o trámites innecesarios existentes en la Administración Pública. Presidencia de la República [Colombia]. Diario Oficial No. 42.137 de 6 de diciembre de 
1995. Recuperado de https://www.funcionpublica. gov.co/eva/gestornormativo/norma.php?i=1208

Decreto 427 (1996, marzo 6). Por el cual se reglamentan el Capítulo II del Título y el Capítulo XV del Título II del Decreto 2150 de 1995. Presidencia de la República [Colombia]. Diario Oficial No. 42.736 de 6 de marzo de 1996. Recuperado de http:// www.suin-juriscol.gov.co/viewDocument.asp?id $=1095642$

Díaz, E. (1958). La Responsabilidad de los Administradores de las Sociedades Anónimas [Tesis de Doctorado]. Bogotá: Escuela Tipográfica Salesiana.

Gaitán Sánchez, O. M. (2014). Guía práctica de las entidades sin ánimo de lucro y del sector solidario. Bogotá: Cámara de Comercio. Recuperado de http://hdl.handle.net/11520/8345

Garrigues, J. (1947). Tratado de Derecho Mercantil (Tomo I). Madrid: Revista de Derecho Mercantil.

Hinestrosa, F. (2013). Autonomía privada y tipicidad contractual. Revista de Derecho Privado, 24, 3-13. Recuperado de https://revistas.uexternado.edu.co/ index.php/derpri/article/view/3300

Jaramillo, J. (2010). Entidades sin ánimo de lucro. Características y aplicaciones del régimen tributario. Bogotá, Colombia: Legis S.A.

Legis (2001). Responsabilidad de los Administradores de Sociedades (1. ${ }^{\mathrm{a}}$ Ed.) [Eruditos Prácticos]. Barreto Rodríguez, J. V., y Chávez García, M. F. (Eds.). Bogotá, Colombia: Legis S.A.

León, E. (2015). Principios y Fuentes del Derecho Comercial Colombiano. Bogotá, Colombia: Universidad Externado de Colombia.

Ley 57 (1887, abril 15). Sobre adopción de códigos y unificación de la legislación nacional. Congreso de la República [Colombia]. Diario Oficial No. 7.019 del 20 de abril de 1887. Bogotá. Recuperado de https:// www.funcionpublica.gov.co/eva/gestornormativo/ norma_pdf.php?i=39535

Ley 22 (1987, marzo 12). Por la cual se asigna una función. Congreso de la República [Colombia]. Diario Oficial No. 37812 del 12 de marzo de 1987. Bogotá. Recuperado de https://www.funcionpublica.gov. co/eva/gestornormativo/norma_pdf.php?i=262

Ley 222 (1995, diciembre 20). Por la cual se modifica el Libro II del Código de Comercio, se expide un nuevo régimen de procesos concursales y se dictan otras disposiciones. Congreso de la República [Colombia]. Diario oficial No. $42.156 \mathrm{del} 20 \mathrm{de}$ diciembre de 1995. Bogotá. Recuperado de http:// www.secretariasenado.gov.co/senado/basedoc/ ley_0222_1995.html

Ley 599 (2000, julio 24). Por la cual se expide el Código Penal. Congreso de la República [Colombia]. Diario Oficial No. 44.097 del 24 de julio del 200o. Bogotá. Recuperado de http://www.secretariasenado.gov. co/senado/basedoc/ley_0599_200o.html

Llebot, O. (2008). Deberes y Responsabilidades de los Administradores. En E. Beltrán (Ed.), La Responsabilidad de los Administradores (2. ${ }^{\text {a }} \mathrm{Ed}$.) (pp. 2345). Valencia, España: Tirant Lo Blanch.

Neira Archila, L. C. (1988). Alcance de las Responsabilidades de los administradores y miembros de las Juntas Directivas. En Cámara de Comercio de Bogotá (Ed.), Los Consorcios ... Responsabilidad de los Administradores de Sociedades [Simposio Nacional sobre Sociedades - 1987] (pp. 155-164). Bogotá: Presencia.

Pérez, A. (1966). Teoría general de las obligaciones (3. ${ }^{\text {a }}$ Ed.). Bogotá: Temis.

Preciado, D. (2004). Indemnización de perjuicios, responsabilidad civil contractual extracontractual $y$ delictual, Tomo II. (3. ${ }^{\text {a }}$ Ed). Bogotá, Colombia: Editorial librería ediciones del profesional.

Reyes, F. (1996). Reforma al Régimen de sociedades y concursos. Bogotá, Colombia: Cámara de Comercio de Bogotá.

Santos Ballesteros, J. (1988). Elementos constitutivos y exonerativos de la responsabilidad civil y jurisprudencia. En Cámara de Comercio de Bogotá (Ed.), Los Consorcios ... Responsabilidad de los Administradores de Sociedades [Simposio Nacional sobre Sociedades - 1987] (pp. 195-206). Bogotá, Colombia: Presencia.

Sentencia T-338 (1993, agosto 24). Acción de Tutela [Expediente T-12.031]. Magistrado Ponente: Alejandro Martínez Caballero. Corte Constitucional [Colombia]. Recuperado de https://www.corteconstitucional.gov.co/relatoria/1993/T-338-93.htm

Sentencia C-o83 (1995, marzo 1ํ). Analogía [Expediente No. D-665]. Magistrado Ponente: Carlos Gaviria Díaz. Corte Constitucional [Colombia]. Recuperado de https://www.corteconstitucional.gov.co/ relatoria/1995/C-083-95.htm

Sentencia T-468 (2003, junio 5). Acción de Tutela [ExpedienteT-515421].MagistradoPonente:Rodrigo Escobar Gil. Corte Constitucional [Colombia]. 
Recuperado de https://www.corteconstitucional. gov.co/relatoria/2003/T-468-03.htm

Sentencia, Sala de Casación Civil. (2011, junio 20). Responsabilidad de los administradores art. 24 Ley 222 de 1995 - solidaria e ilimitada. [Expediente 05001-3103-005-2000-00177-01]. Magistrada Ponente: Dra. Ruth Marina Díaz Rueda. Corte Suprema de Justicia [Colombia].

Superintendencia de Sociedades. (2016, marzo14). Régimen aplicable a las Entidades sin Ánimo de Lucro. [Oficio 220-053767]. Recuperado de http://hdl.handle.net/11520/15411

Superintendencia de Sociedades. (1997, julio 18). Circular Externa No. oog: Los administradores (Ley 222 de 1995). Recuperado de https://www.supersociedades.gov.co/nuestra_entidad/normatividad/normatividad_circulares/535.pdf

\section{Notas}

1 Ver los artículos 26, 39, 45, 49, 52, 58, 71,78, 103 entre otros de la Constitución Política de Colombia.

2 Artículo 641 del Código Civil Colombiano, "Fuerza Obligatoria de los Estatutos. Los estatutos de una corporación tienen fuerza obligatoria sobre ella, y sus miembros están obligados a obedecerlos bajo las penas que los mismos estatutos impongan".

3 Artículo 650 del Código Civil Colombiano, "Normativa de las fundaciones de beneficencia. Las fundaciones de beneficencia que hayan de administrarse por una colección de individuos se regirán por los estatutos que el fundador les hubiere dictado; $y$ si el fundador no hubiere manifestado su voluntad a este respecto, o sólo la hubiere manifestado incompletamente, será suplido este defecto por el presidente de la Unión”.

4 Va más allá que la vigilancia, esta puede incluir una visita de carácter administrativo por parte de un agente del Estado, a través de la cual puede solicitar documentos e incluso pedir la declaración del representante legal si a ello hubiere lugar.

5 Constituye el mayor grado de vigilancia, podría llamarse la jerarquía de la supervisión del Estado, y en este estadio puede solicitar incluso la toma de posesión para liquidar o administrar una entidad. Ejemplo "DMG-Caso pirámides en Colombia".
6 El Estado observa la conducta de los particulares sin que dicha vigilancia tenga injerencia en sus actividades como entidad.

7 La función de inspección, control y vigilancia, delegada a los gobernadores de los departamentos (Decreto 1529 de 1990) y en el Alcalde Mayor de Bogotá (Decreto 059 de 1991).

8 En el cumplimiento de la función delegada por el Presidente de la República en cuanto al control, inspección y vigilancia de la ESAL, le está permitido al Alcalde, decretar o pedir la separación del cargo de representantes legales o de cualquiera de los miembros de las entidades cuando se haya probado que se realizaron actos distintos al objeto y naturaleza para el cual fue creada.

9 Conformadas por personas de una misma especialidad, profesión u oficio. Por ejemplo, abogados, médicos, ingenieros, contadores, conductores, comunicadores sociales.

10 Constituidas por quienes adelantan actividades propias del campo, tales como la agricultura, avicultura, ganadería, pecuarias, porcicultura, con el objetivo de satisfacer los intereses de sus asociados y contribuir al desarrollo del sector rural.

11 Creadas para ayudar a las personas que no tienen o que son de bajos recursos.

12 Son creadas con la idea de fortalecer y desarrollar actividades que promuevan el desenvolvimiento y crecimiento de los jóvenes en la sociedad.

13 Creadas para promover una mejor manera de vivir en comunidad.

14 Se crean con la finalidad de promover mecanismos de democracia y participación en los distintos escenarios de la gestión pública.

15 Se crean con la finalidad de promover el desarrollo armónico del individuo en la sociedad.

16 Nacen con la finalidad de brindar esparcimiento y diversión a la sociedad o a un sector de esta. Por ejemplo, los clubes sociales.

17 Persona designada para la toma de decisiones y responsabilidad sobre la sociedad. Su función resulta de vital importancia, pues su acción compromete a la entidad, a la persona jurídica, y, llegado el caso, hasta ella misma.

18 Reglamentadas mediante la Ley 850 de 2003. 
19 En el cual se señala que no es admisible la disolución y liquidación por mera voluntad de sus asociados, sino que será por mandato legal, en el caso de las fundaciones.

20Modificada por las leyes 890 de 2004, 964 de 2005 y 1357 de 2009. 